D.O.I.: $10.3895 / \mathrm{S} 1808-04482010000300010$

\title{
APRENDIZADO INTERATIVO INFLUENCIANDO NO PROCESSO DE GERAÇÃO DA INOVAÇÃO: ESTUDO EM UM AGLOMERADO PRODUTIVO DE EMPRESAS
}

\section{INTERACTIVE LEARNING INFLUENCING IN THE PROCESS OF INNOVATION GENERATION: STUDY IN A PRODUCTIVE CLUSTER}

\author{
Leozenir Mendes Betim ${ }^{1}$; Luis Mauricio Martins de Resende ${ }^{2}$ \\ ${ }^{1}$ Centro de Ensino Superior dos Campos Gerais - CESCAGE - Ponta Grossa - Brasil \\ leo@cescage.edu.br \\ ${ }^{2}$ Universidade Tecnológica Federal do Paraná - UTFPR - Ponta Grossa - Brasil \\ lmresende@utfpr.edu.br
}

\begin{abstract}
Resumo
O presente artigo tem por objetivo identificar as formas de relações interempresariais, bem como verificar os fatores que limitam as empresas de um Aglomerado Produtivo (Cluster) a aderirem a relacionamentos de interação mais sólidos, capazes de incrementarem a inovação. A pesquisa de campo contemplou um universo de 36 MPME's que atuam no setor madeireiro. Utilizou-se um questionário com questões estruturadas e anotadas sequencialmente. Constitui-se em uma pesquisa quantitativa e qualitativa, de natureza interpretativa, utilizando-se de um levantamento (survey). Entre os principais resultados, constatou-se que apesar das vantagens da literatura, o Aglomerado Produtivo em estudo não vem se mostrando como um mecanismo facilitador do processo de articulação e aprendizado interativo, prevalecendo no ambiente interno das empresas os mecanismos do tipo "learning by doing", obtidos pelas experiências acumuladas e habilidades adquiridas localmente, possibilitando a definição de adaptações e melhorias tecnológicas. Embora se verifique que uma parcela significativa das empresas preocupa-se com a inovação em produto, processo ou equipamento, observa-se uma ausência praticamente completa de atividades de P\&D integradas em favor da tecnologia junto a centros tecnológicos de pesquisa e universidades do tipo "learning by interacting".
\end{abstract}

Palavras-chave: aglomerações produtivas; aprendizado interativo; inovação.

\section{Introdução}

Uma das tendências que vem se solidificando no processo de reestruturação industrial é a que diz respeito as formas de relações entre empresas. Nesse sentido, as relações de cooperação são incrementadas visando reduzir justamente as dificuldades que se traduzem como "custos de transação" para as empresas, isto é, os custos que vão além dos custos de produção. 
A flexibilização dos processos produtivos acaba criando novas possibilidades de desenvolvimento para as empresas e nesse cenário as possibilidades exigem também novas competências, como a capacidade para estabelecer relações interempresariais, compartilhar conhecimentos de forma a estimular as interações voltadas para os processos de aprendizagem interativa.

Muitos são os autores que preconizam que a intensificação de relações cooperativas permite o crescimento de laços de confiança e a percepção dos benefícios advindos de soluções conjuntas, tanto no âmbito empresarial, quanto no que diz respeito a coletividade e ao desenvolvimento regional.

Lundvall e Johnson (2000) definem a forma de aprendizado que surge da relação da empresa com outras empresas de "learning by interacting”. Para esses autores o estabelecimento de relações de cooperação entre empresas pode ser um instrumento importante para estimular o crescimento dessas empresas e da economia regional, uma vez que essa cooperação permite a elas a obtenção de ganhos de escala e escopo e ao gerar externalidades positivas, acaba minimizando os problemas comuns a todas elas. Dessa forma, abordam que a principal vantagem dessas interações é a construção de um conhecimento tácito que só é possível pela proximidade espacial, e cuja transferência depende do contexto social e das instituições estabelecidas nessa localidade.

Esta presumível expansão das aglomerações empresariais que fazem parte da paisagem de todos os países independentes de seu estágio de desenvolvimento implica na necessidade de revisão dos conceitos relativos às formas de organização e cooperação entre as empresas.

Diante desse contexto o presente artigo tem por objetivo identificar as formas de relações interempresariais, bem como verificar os fatores que limitam as empresas de um Aglomerado Produtivo (Cluster) a aderirem a relacionamentos de interação mais sólidos, capazes de incrementarem a inovação.

\section{Aglomeração produtiva de empresas}

Britto (2000) define os aglomerados ou arranjos produtivos locais como concentrações geográficas de atividades econômicas similares e/ou fortemente inter-relacionadas ou interdependentes. Esta aglomeração espacial econômica já formulada por Marshall em 1920, originalmente costumava ser caracterizada a partir dos desdobramentos da análise dos Distritos Industriais.

Schmitz e Nadvi (1999) apresentam uma definição simples e operacional ao termo aglomerados produtivos (clusters), como sendo apenas uma concentração setorial e espacial de firmas com ênfase em uma visão de empresas com entidades conectadas nos fatores locais para a competição nos mercados globais. Diante dessa afirmação, Amato Neto (2000) complementa que os 
“clusters" já podem ser considerados como formas mais estruturadas de aglomeração de empresas, envolvendo também fornecedores de matéria-prima e equipamentos, canais de distribuição e de assistência a seus produtos.

Para Haddad (2001) não faz sentido falar de um aglomerado produtivo (cluster), sem contextualizá-lo espacialmente. Isto é, um cluster numa região X é diferente de um cluster na região Y. Entre os motivos dessa diferenciação, o autor aponta o nível organizacional dos produtos, a qualidade da mão-de-obra, a logística de transporte, os indicadores de desenvolvimento sustentável, os insumos, os conhecimentos científicos e tecnológicos, etc.

Verifica-se que a grande diferença existente entre o que é definido por aglomerado ou cluster em um simples agrupamento de empresas em um mesmo local, diz respeito à dedicação das empresas para uma mesma linha de produtos e a existência de sinergia entre as mesmas.

Entre os benefícios decorrentes da proximidade geográfica entre clientes e fornecedores, Gianesi e Correa (1996) citam a otimização da utilização de equipamentos e insumos através de aconselhamento informal pelo fornecedor do mesmo, treinamento formal e informal de funcionários, redução do tempo de espera de assistência técnica e maior personalização no atendimento. Outro aspecto considerado por McCormick (1999 apud Debiasi, 2001) é que os clusters facilitam a criação de mão-de-obra especializada na região, visto que esta mão-de-obra especializada e experiente traz uma série de vantagens tanto para os trabalhadores como para as empresas.

Segundo Porter (1999), uma característica muito favorável dos clusters é o acesso às informações, pois essas informações quando utilizadas de maneira correta, podem determinar o sucesso das empresas, pois através delas é possível aumentar a produtividade da empresa, acelerar as inovações, acelerar a transferência de know-how entre as empresas e atender melhor e mais rapidamente as necessidades dos clientes.

Suzigan (2004) ao referir-se a aglomerados de empresas como um Arranjo Produtivo Local (APL) considera a cooperação como um dos princípios básicos de funcionamento de um arranjo, cujo sucesso pressupõe a valorização dos aspectos sócio-culturais da região e a disponibilidade de apoio técnico e econômico, porém não se deve considerar que as empresas locais não tenham ou não desejem competir entre si para a conquista de posições mais expressivas no mercado, que é uma das regras do sistema capitalista em que estão inseridas.

Outro aspecto considerado é que a concentração de empresas afins em uma determinada região favorece o marketing coletivo. Este acontece através não só da publicidade em si, mas através de feiras, revistas especializadas e entre outros meios (PORTER, 1999). Na visão do mesmo autor, um cluster será, então, tão mais completo quanto mais atender às características 
anteriormente mencionadas. Porém, mesmo incompletos, os clusters já apresentam vantagens com relação as empresas competindo isoladamente.

\section{Aprendizado interativo e inovação}

Os aglomerados facilitam a inovação, devido ao relacionamento próximo com parceiros e fornecedores, à facilidade de monitoramento dos concorrentes dentro do cluster, a grande disponibilidade de informações, a facilidade na observação de tendências tecnológicas e às mudanças de hábitos ou necessidades dos consumidores.

Porter (1999) acrescenta que as empresas de um cluster adquirem componentes e serviços com mais rapidez, facilitando a inovação. Estas empresas conseguem realizar experiências a custos mais baixos, diminuindo os riscos financeiros da inovação. Em contrapartida, o mesmo autor aborda duas situações em que a inovação pode ser retardada nos clusters: quando a competição é reduzida e quando as inovações são radicais a tal ponto que podem invalidar uma parte do cluster ou até mesmo o próprio cluster como um todo, como é o caso de novos produtos que acarretam a descontinuidade de produtos antigos.

Cassiolato e Szapiro (2002) salientam que a capacidade de gerar inovações tem sido identificada como um fator chave do sucesso de empresas, sendo que tal capacidade é obtida através de intensa interdependência entre os diversos atores, produtores e usuários de bens, serviços e tecnologias, sendo facilitada pela especialização em ambientes sócio-econômicos comuns. Nessa mesma linha de pensamento Cassiolato (2000, p.22) defende que "uma política de desenvolvimento sem investimento em tecnologia é impossível".

Barquero (2002, p.21), salienta que "a introdução de inovações que são sempre um resultado coletivo da cooperação tácita entre as empresas, leva o aumento da produtividade e da competitividade das economias locais".

Na concepção de Campos et al. (2002) o aprendizado pode ser considerado como um processo fundamental para a construção de novas competências e obtenção de vantagens competitivas, o qual através da busca de novas fontes de informação e outros mecanismos capacita tecnologicamente às firmas e estimula as suas atividades produtivas e inovativas. Dessa forma, o aglomerado contribui para a aprendizagem coletiva, difusão do conhecimento e da tecnologia, sendo um ambiente em que a integração e compartilhamento são compartilhados para busca de soluções e respostas.

Na visão de Lemos (2003) o processo de geração de conhecimentos e de inovação vai implicar: no desenvolvimento de capacitações científicas, tecnológicas e organizacionais e esforços substanciais de aprendizado com experiência própria, no processo de produção (learning-by-doing), comercialização e uso (learning-by-using), na busca incessante de novas soluções técnicas nas 
unidades de pesquisa e desenvolvimento ou em instâncias menos formais (learning-by-searching); e na interação com fontes externas, como fornecedores de insumos, componentes e equipamentos, clientes, usuários, consultores, sócios, universidades, institutos de pesquisa, agências e laboratórios governamentais (learnin-by-interacting); em interações específicas para a subcontratação de insumos, componentes ou produtos (learning-by-subcontracting); ou mesmo em processos de cópias de concorrentes (learning-by-imitation).

Lundvall e Johnson (2000) preconizam que o fluxo de conhecimento tácito e acumulativo local desenvolve as economias de aprendizagem de duas maneiras:

a) Pelas fontes internas - aprender fazendo (learning by doing),isto é, experiências próprias no processo de produção. O aprendizado ocorre em nível interno na firma quando as novas maneiras de fazer as coisas ou de realizar novos serviços resultam no surgimento de algo até então inexistente. Ocorrem avanços, surgem melhoramentos, aparecem incrementos que são incorporados aos produtos e processos existentes; aprender usando (learning by using), em que o aprendizado pela utilização do produto gera condições para mudanças contínuas. Através do uso são conhecidos os limites, problemas, qualidades etc.dos produtos, permitindo, através do sistema de informação, o aperfeiçoamento e melhoramento de suas qualidades; e aprender pesquisando (by searching), que envolve atividades de Pesquisa e Desenvolvimento (P\&D) na firma;

b) Pelas fontes externas - aprendizado por interação (learning by interaction). Constitui o aprendizado decorrente de relações entre a firma e seus consumidores e fornecedores em processos inovativos. Processos interativos entre agentes permitem a troca de informações, ações conjuntas, divisão de responsabilidades, estabelecimento de código e procedimentos, que resultam em alterações no status quo dos produtos e processos, representando ganhos econômicos para as empresas, os quais surgem de relações duradouras com clientes ou fornecedores, criando um aprendizado coletivo para a melhoria dos métodos de produção, qualidade dos produtos e maior capacitação tecnológica. Para os autores o estabelecimento de relações de cooperação entre

empresas "learning by interacting”, pode ser um instrumento importante para estimular o crescimento dessas empresas e da economia regional, uma vez que essa cooperação permite a elas a obtenção de ganhos de escala e escopo e ao gerar externalidades positivas, acaba minimizando os problemas comuns a todas elas.

\section{Aglomerado Produtivo de Telêmaco Borba - PR}

Entre os quatro tipos básicos de aglomerações produtivas apontadas pelo Sepl e Ipardes (2005), o Aglomerado Produtivo de Telêmaco Borba, localizado na região centro-oriental do Paraná, foi identificado e classificado como Vetor de Desenvolvimento Local (VDL), sendo formado por empresas que atuam no segmento econômico de desdobramento de madeira (produção 
de madeira serrada); fabricação de madeira laminada e de chapas de madeira compensada; fabricação de artefatos diversos de madeira e fabricação de móveis sob medida (residencial e escritório).

A capacidade de fomento florestal da KLABIN S.A, juntamente com a prefeitura do município e parcerias de outros agentes locais foi de extrema importância para a formação do aglomerado produtivo madeireiro de 1995 a 2001, gerando por sua vez emprego e renda na região e garantindo melhores perspectivas de sobrevivência das empresas madeireiras no mercado, especialmente das micro e pequenas empresas.

\section{Metodologia e procedimentos}

A pesquisa de campo contemplou um universo de 36 MPME's que atuam no setor madeireiro. Mediante classificação do CNAE (Código Nacional da Atividade Empresarial), essas empresas foram agrupadas de acordo com o segmento econômico atuante, conforme demonstrado no Quadro 1.

Quadro 1 - Número de empresas pesquisadas por segmento econômico da madeira

\begin{tabular}{|l|c|}
\hline \multicolumn{1}{|c|}{ Segmento Econômico da Madeira } & $\begin{array}{c}\text { No }^{\mathbf{0}} \text { empresas } \\
\text { Pesquisadas }\end{array}$ \\
\hline Desdobramento de Madeira e ou /Secagem da madeira & 20 \\
\hline Fabricação de Madeira Laminada e de Chapas de Madeira Compensada & 4 \\
\hline Fabricação de Artefatos Diversos de Madeira & 12 \\
\hline Total & $\mathbf{3 6}$ \\
\hline
\end{tabular}

Fonte: Pesquisa de campo (2007)

Nos casos em que se verificou que a empresa atuava em mais de um segmento econômico, tendo em vista a ocorrência de processos que se complementam em algumas plantas, gerando produtos que podem ser enquadrados também em outros segmentos, adotou-se como critério a classificação pelo segmento econômico com maior valor agregado e maior percentual de produção para empresa.

O método utilizado na pesquisa foi o indutivo, visto que neste tipo de raciocínio a generalização deriva de observações de casos da realidade empírica. Gil (1999, p.28) define o método indutivo como "um processo onde a pesquisa parte do particular e coloca a generalização como o produto posterior do trabalho de coleta de dados particulares".

A abordagem metodológica adotada para a pesquisa é quantitativa e qualitativa de natureza interpretativa, sendo classificada como descritiva, com caráter exploratório. Em função dos procedimentos técnicos adotados, classifica-se como levantamento (survey), envolvendo a interrogação direta do proprietário, gerente de produção ou gerente/coordenador administrativo da empresa. Utilizou-se como instrumento de coleta de dados uma entrevista estruturada com suporte de um questionário. 


\section{Descrição e análise dos resultados}

Serão apresentadas a partir desse ponto a descrição e análise dos resultados obtidos através dos questionários e entrevistas sobre o elemento central do estudo, buscando identificar as formas de relações interempresariais, bem como verificar os fatores que limitam as empresas de um Aglomerado Produtivo (Cluster) a aderirem a relacionamentos de interação mais sólidos, capazes de incrementarem a inovação.

\section{1. Relação entre as empresas madeireiras}

Uma característica favorável das aglomerações produtivas está no acesso e compartilhamento de informações entre as empresas. Nesse sentido, procurou-se averiguar a questão das relações bilaterais horizontais entre as empresas do aglomerado produtivo. Esses dados são demonstrados na Tabela 1 .

Tabela 1- Relacionamento e troca de informações entre as empresas do aglomerado produtivo de Telêmaco Borba

\begin{tabular}{|c|c|c|c|c|c|c|c|c|c|}
\hline Relacionamento/Troca de & $\begin{array}{c}\text { Freq. } \\
(\%)\end{array}$ & \multicolumn{8}{|c|}{$\mathrm{N}^{0}$ de empresários } \\
\hline \multirow{2}{*}{$\begin{array}{l}\text { Relacionamento extra- } \\
\text { profissional }\end{array}$} & & $2-4$ & $4-8$ & 8 - 12 & $12-16$ & $16-20$ & $20-24$ & $24-28$ & $28-32$ \\
\hline & $95 \%$ & $5 \%$ & $56 \%$ & $15 \%$ & $5 \%$ & $0 \%$ & $7 \%$ & $2 \%$ & $10 \%$ \\
\hline Relacionamento empresarial & $98 \%$ & $36 \%$ & $36 \%$ & $24 \%$ & $2 \%$ & $0 \%$ & $2 \%$ & $0 \%$ & $0 \%$ \\
\hline Troca informal de informações & $98 \%$ & $17 \%$ & $57 \%$ & $19 \%$ & $2 \%$ & $0 \%$ & $2 \%$ & $2 \%$ & $0 \%$ \\
\hline Troca formal de informações & $49 \%$ & $52 \%$ & $33 \%$ & $14 \%$ & $0 \%$ & $0 \%$ & $0 \%$ & $0 \%$ & $0 \%$ \\
\hline
\end{tabular}

Fonte: Pesquisa de campo (2007)

Constatou-se ser acima de $90 \%$ os entrevistados que responderam que possuem relacionamento extra-profissional, (amizade e interação social caracterizada por encontros informais com outros empresários), relacionamento empresarial e praticam trocas informais de informações, envolvendo em alguns casos aspectos relacionados a novas tecnologias do mercado, disponibilidade de créditos, concorrência, qualidade e especificação do produto, máquinas e equipamentos. Esse universo de relacionamento, porém, se restringe a não mais que 16 empresários.

A troca formal de informações é menos significativa, visto que $49 \%$ dos entrevistados responderam trocar informações formais principalmente com empresários do mesmo segmento a respeito de questões que envolvem a aquisição e transporte da madeira, canais comuns de distribuição, exportação e outras que exigem um grau maior de discussão e formalidade.

Em relação à frequiência da troca formal ou informal de idéias ou discussão de estratégias empresariais, verificou-se que $69,4 \%$ dos entrevistados realizam ocasionalmente e $27,8 \%$ frequentemente. Nessa troca de informações são abordadas questões sobre: inovação tecnológica das máquinas e equipamentos, qualidade e especificação do produto, novos produtos, otimização e 
preço da matéria-prima, contratação de mão-de-obra, legislações ambientais, questões mercadológicas e financeiras e outras relacionadas ao setor madeireiro.

Cerca de $63,9 \%$ das empresas responderam que ocasionalmente visitam outras empresas do aglomerado produtivo e 33,3\% mencionaram ser freqüente essas visitas, porém de forma isolada com algumas empresas do mesmo segmento e que possuem maior efetividade. Nessa mesma linha, $58,3 \%$ das empresas responderam que ocasionalmente permitem o acesso de seu local de trabalho para visitas de outras empresas do aglomerado e 41,7\% destacaram que essas visitas são freqüentes, principalmente de empresas do mesmo segmento econômico.

As relações comerciais e a troca de informações mostram-se ainda tímidas, ocorrendo de forma isolada entre empresas do aglomerado. Em alguns casos as relações surgem a partir de interações sociais. Isso é corroborado quando se constatou que 47,2\% dos entrevistados mantêm interação social em reuniões semanais envolvendo os empresários (casa de um determinado empresário), 30,6\% em clubes recreativos e esportivos, $11,1 \%$ em atividades culturais, 8,33\% em encontros informais de vizinhança; 5,6\% em igrejas, 5,6\% em reuniões familiares. Do universo das 36 empresas entrevistadas, 22,2\% mencionaram que não mantém nenhum tipo de interação social com as empresas do aglomerado produtivo, preferindo que esse tipo de interação ocorra somente com os funcionários da própria empresa.

Considerando os resultados apresentados, observa-se que há troca de informações no aglomerado produtivo, porém essa incidência não está sendo suficiente para incrementar aspectos mais evoluídos de integração que propiciem vantagens competitivas para as empresas concentradas. Tal fato é evidenciado, onde se percebe que são até 12 as empresas que interagem, sendo que as demais apresentam uma postura de reserva, com comportamento mais voltado à competitividade do que à cooperação. Dessa forma, observa-se que o aglomerado ainda se apresenta fechado e com pouco dinamismo nas interações entre as empresas. Nessa linha, Porter (1999) preconiza que além da troca de informações, deve existir uma parceria que envolva vários aspectos e etapas das relações empresariais.

A seguir são apresentadas através da Tabela 2 as formas de cooperação entre as empresas do aglomerado produtivo mais freqüentes.

Tabela 2 - Formas de cooperação entre as empresas do aglomerado produtivo de Telêmaco Borba

\begin{tabular}{l|c|c}
\hline Formas de cooperação & $\begin{array}{l}\mathbf{N}^{\circ} \text { Cit. } \\
\text { (Sim) }\end{array}$ & $\begin{array}{l}\text { Freq. (\%) } \\
\text { (Sim) }\end{array}$ \\
\hline Na produção & 15 & $41,7 \%$ \\
Na compra de matéria-prima & 11 & $30,6 \%$ \\
Na comercialização de produtos & 9 & $25,0 \%$ \\
Na exportação de produtos & 7 & $19,4 \%$ \\
Na importação de equipamentos, máquinas e outros produtos & 1 & $2,8 \%$
\end{tabular}




\begin{tabular}{l|c|c} 
No arrendamento de maquinário & 6 & $16,7 \%$ \\
No desenvolvimento de produtos & 4 & $11,1 \%$ \\
No desenvolvimento tecnológico & 7 & $19,4 \%$ \\
No marketing setorial & 4 & $11,1 \%$ \\
No treinamento de mão-de-obra & 9 & $25,0 \%$ \\
Na troca ou empréstimo de materiais & 20 & $55,6 \%$ \\
Na organização de feiras & 3 & $8,3 \%$ \\
Na negociação com o Governo & 5 & $13,9 \%$ \\
Na negociação com o Sindicato & 19 & $52,8 \%$ \\
Na solução de problemas comuns & 17 & $47,2 \%$ \\
Outros (especificar) & 4 & $11,1 \%$ \\
\hline
\end{tabular}

Fonte: Pesquisa de campo (2007)

Observa-se que a cooperação entre as empresas se dá na troca ou empréstimo de materiais comuns ao processo produtivo dos segmentos econômicos em percentual significativo $(55,6 \%$ dos entrevistados).

Quanto aos problemas comuns presentes no distrito industrial, como transporte, energia, telefonia e outros, cerca de 47,2\% das empresas mencionaram cooperarem no sentido da busca de soluções junto à prefeitura do município.

Na negociação com o sindicato, 52,8\% das empresas cooperam em aspectos relacionados à negociação salarial junto ao Sindicato dos Trabalhadores (SINTRACONTB) e negociações coletivas junto ao Sindicato Patronal (SINDIMATEL).

Entre as empresas que mencionaram cooperar na produção $(41,7 \%)$, observou-se que a questão da falta de matéria-prima em algumas situações é suprida por empresas que utilizam madeira com mesma especificação (diâmetro), destacando-se por sua vez tal fator como um tipo de cooperação relevante para as empresas. Uma das empresas do segmento de desdobramento de madeira (produção de madeira serrada), citou que esporadicamente em casos de deficiência produtiva, busca alternativas de parceria temporária com outra empresa do mesmo segmento.

Em relação à compra de matéria-prima, verificou-se que 30,6\% das empresas cooperam entre si, porém essa prática é mais frequente entre empresas do mesmo porte e que operam no mesmo segmento econômico, utilizando-se por sua vez as mesmas espécies de madeira.

Cerca de $25 \%$ das empresas cooperam na comercialização de produtos, sendo essa prática mais freqüente entre empresas que produzem a mesma linha de produtos. Uma das empresas ressaltou que essa forma de cooperação é realizada esporadicamente.

Quanto ao desenvolvimento de novos produtos, verificou-se que $11,1 \%$ das empresas, notadamente as do segmento de artefatos diversos, cooperam entre si, porém isso acontece de forma isolada entre empresas com processos produtivos mais aprimorados. O mesmo acontece na questão do desenvolvimento tecnológico, quando se observa que somente 19,4\% das empresas cooperam 
entre si.

Em termos de arrendamento de maquinário, 16,7\% das empresas mencionaram que cooperam quando necessitam de máquinas para uma produção em maior escala.

Quanto ao treinamento de mão-de-obra, percebeu-se que $25 \%$ das empresas utilizam essa prática de cooperação quando se trata de cursos voltados à área de produção e especificamente na área de segurança do trabalho. Uma das empresas entrevistadas mencionou que empresta máquinas e equipamentos em treinamentos específicos que envolvem outras empresas do setor.

Verificou-se que 19,4\% das empresas cooperam na exportação de produtos quando enviados para canais comuns de comercialização em países como Indonésia, Canadá, China, Estados Unidos, Vietnã ou parte da Europa. Uma determinada empresa do segmento de molduras mencionou que esporadicamente ocorre a exportação em containers com uma empresa do mesmo segmento.

Já em relação à cooperação na importação de equipamentos, máquinas e outros produtos, somente uma empresa mencionou utilizar essa prática. Entretanto, os resultados evidenciados são contraproducentes a essa prática, isto é não demonstraram a presença desse tipo de cooperação.

No tocante ao marketing setorial, verificou-se que somente $11,1 \%$ das empresas cooperam na divulgação dos produtos do município e 8,3\% cooperam na organização de feiras.

Em relação à negociação com o governo, percebeu-se que essa forma de cooperação prevalece em 13,9\% das empresas, restringindo-se essas negociações com o governo municipal no que tange a busca de melhores condições de infra-estrutura para o distrito industrial.

Entre outras formas de cooperação, 11,1\% das empresas citaram a contratação de mão-deobra (aproveitamento de mão-de-obra especializada), compra e venda de madeira serrada, lenha/resíduos e discussão sobre as melhores especificações da madeira ofertada pela Klabin Florestal S.A.

Do universo das 36 empresas entrevistadas, $11,1 \%$ declararam não cooperarem em nenhuma atividade comercial, organizacional ou administrativa, pois preferem que as decisões estratégicas sejam tomadas pelo próprio proprietário ou sócio da empresa. Neste contexto, denota-se que mesmo a literatura apresentando uma vasta contribuição sobre os benefícios da cooperação entre empresas de um aglomerado como alternativa estratégica, verificou-se que as empresas atribuíram uma resposta contraproducente, isto é, não mostraram estarem envolvidas em processos mais evoluídos de cooperação.

Em relação aos fatores que influenciam ou dificultam as empresas a aderirem a relacionamentos cooperativos interempresariais mais consistentes, constatou-se os seguintes resultados:

a) 56,1\% mencionam a falta de um articulador (órgão) legal que fomente a cooperação e que seja o gestor dos diversos inter-relacionamentos entre as empresas madeireiras; 
b) $56,1 \%$ consideram a falta de hábito em cooperação entre os empresários locais;

c) 39\% abordam o medo de a cooperação torná-las mais frágeis perante a concorrência;

d) 53,7\% mencionam a desconfiança entre as empresas locais;

e) $36,6 \%$ consideram a disputa pelos mesmos mercados;

f) $31,7 \%$ apontam o fato das empresas não reconhecerem a cooperação como forma do aumento da competitividade.

Cabe ressaltar que as empresas entrevistadas mencionaram ainda a falta de tempo, a falta de vontade, a falta de visão empreendedora e a resistência como fatores que se constituem em entraves para estimular a cooperação e a aprendizagem interativa entre as empresas do aglomerado produtivo.

\subsection{Pesquisa, desenvolvimento e inovação (P\&D\&I)}

As relações com Centros Tecnológicos de Pesquisa, Universidades e outras instituições afins é praticamente inexistente no aglomerado produtivo, restringindo essas relações a uma parcela pequena de empresas, como mostrado na Tabela 3.

Tabela 3 - Relações de intercâmbio com centros de pesquisa, universidade e instituições afins pelas empresas do aglomerado de Telêmaco Borba

\begin{tabular}{l|c|c|c|c}
\hline \multirow{2}{*}{ Formas de interação } & \multicolumn{3}{|l}{ Freqüência $(\%)$} & \multicolumn{2}{l}{} \\
\cline { 2 - 5 } & Inexistente & Rara & Anual & Mensal \\
\hline Certificação florestal da cadeia de custódia & $63,9 \%$ & $0,0 \%$ & $36,1 \%$ & $0,0 \%$ \\
Caracterização e seleção de matéria-prima & $94,4 \%$ & $2,8 \%$ & $2,8 \%$ & $0,0 \%$ \\
Desenvolvimento de novos produtos & $97,2 \%$ & $2,8 \%$ & $0,0 \%$ & $0,0 \%$ \\
Desenvolvimento de novos processos & $97,2 \%$ & $2,8 \%$ & $0,0 \%$ & $0,0 \%$ \\
Aproveitamento de resíduos industriais & $97,2 \%$ & $2,8 \%$ & $0,0 \%$ & $0,0 \%$ \\
Outras (especificar) & $92,7 \%$ & $7,3 \%$ & $0,0 \%$ & $0,0 \%$ \\
\hline
\end{tabular}

Fonte: Pesquisa de campo (2007)

Entre as relações existentes junto às entidades de pesquisa, verificou-se que a certificação da cadeia de custódia faz parte do universo de 36,1\% das empresas. Essa certificação é destinada a empreendimentos que processam e comercializam produtos florestais certificados, onde devem existir garantias de controle de procedência, manuseio e rastreamento da matéria-prima utilizada em todas as etapas de produção, desde a floresta até o produto final. Os produtos das empresas certificadas recebem o selo credenciado pelo Conselho de Manejo Florestal - FSC (Forest Stewardship Council), instituição internacional, sem fins lucrativos, que identifica para o consumidor que o produto está seguindo rigorosos padrões ambientais, sociais e econômicos. Aqui no Brasil, as empresas que possuem o selo FSC são monitoradas anualmente pelo programa de certificação florestal do IMAFLORA (Instituto de Manejo e Certificação Florestal e Agrícola).

A caracterização e seleção de matéria-prima é realizada com freqüência rara em uma 
empresa do segmento de desdobramento de madeira em parceria com a Klabin Florestal S.A e Universidade Federal do Rio Grande do Sul (UFRGS). Outra empresa do segmento de fabricação de madeira laminada e de chapas de madeira compensada mencionou utilizar essa prática com freqüência anual junto a Universidade Federal do Paraná (UFPR).

O desenvolvimento de novos produtos é realizado por uma empresa do segmento de fabricação de artefatos diversos da madeira com freqüência rara junto a UFPR. Já uma empresa do segmento de desdobramento de madeira mencionou manter contato mensal com a UFPR para o desenvolvimento de novos processos que envolvem a secagem da madeira.

O contato sobre o aproveitamento de resíduos industriais é realizado por uma empresa do segmento de artefatos diversos da madeira com freqüência rara junto a entidades como SENAI e EMBRAPA.

Outras formas de interação foram citadas por um número pequeno de empresas (não mais que 03 empresas) como: contratação de estagiários do curso de Engenharia da Madeira da UFPR; testes de resistência dos materiais junto ao Instituto de Tecnologia do Paraná (TECPAR) e testes de colagem junto a uma instituição localizada na França.

Do universo das empresas que não mantêm nenhuma forma de interação com Centros de Pesquisa e/ou Universidades, apontaram-se os seguintes motivos:

a) 48,2\% não têm necessidade, pois julgam serem empresas de pequeno porte, cujo processo ou produto não exige qualquer forma de inovação;

b) $37 \%$ alegam que as instituições de ensino e pesquisa a nível regional nunca as procuraram com uma proposta de interesse para a empresa;

c) 7,4\% consideram que as instituições locais não possuem a infra-estrutura e qualificação necessária para atender as necessidades de P\&D da empresa, visto que a instituição SENAI está mais voltada para área de celulose e papel e a Faculdade de Telêmaco Borba (FATEB) não possui cursos voltados para área madeireira;

d) 7,4\% contam com fornecimento externo de informações de P\&D.

Uma parcela pequena de empresas mencionou a distância do aglomerado em relação aos centros de pesquisa, o conhecimento dos proprietários e/ou e as informações confidenciais e estratégias da empresa como motivos que justificam a falta de interação. Dessa forma, verifica-se que os processos de aprendizagem ocorrem através de experiências próprias no processo de produção, o que na realidade limita as empresas do aglomerado a incrementarem mudanças contínuas através de fontes externas, como aperfeiçoamento e melhoria dos métodos de produção, qualidade dos produtos e maior capacitação tecnológica. 


\section{Considerações finais}

A partir dos resultados, constata-se que a interação e/ou cooperação entre as empresas é pouco significativa, mostrando-se inconsistente e resumida a aspectos voltados para a solução de problemas comuns básicos.

Existe certo grau de articulação e afinidade entre empresas, porém de forma isolada, notadamente entre empresas do mesmo segmento econômico. Sendo assim, observa-se certa competição com pouca cooperação entre as empresas, devido aos fracos entrelaçamentos existentes entre as mesmas, sendo que as ações conjuntas no local ainda não são satisfatórias. As trocas de informações acontecem com maior relevância, porém não estão sendo suficientes para que saltos qualitativos no desempenho do aglomerado possam ser dados em termos de eficiência coletiva.

Diante desse cenário, infere-se que o nível das relações interempresariais apresenta-se desarticulado, caracterizando-se mais por relações isoladas, o que ocasiona em um baixo nível de ações coletivas aquém do desejado para proporcionar vantagem competitiva às empresas do aglomerado.

Embora a inovação seja um fator significativo para a maioria das empresas, as relações com Centros Tecnológicos de Pesquisa, Universidade e instituições afins para o desenvolvimento de novos processos e produtos do tipo "learning-by-searching" e "learning-by-interacting", são praticamente inexistentes, restringindo a não mais que 05 empresas. Contribui para essa realidade fatores como comportamento individualista e relutante por parte dos empresários de perspectiva de curto prazo e lucros imediatos e de desconfiança em relação ao estabelecimento de parcerias com agentes institucionais, esses considerados como motivos fortes para darem lugar à idéia de aprendizagem interativa. Essa realidade opõe-se ao pensamento de Roetlandt e Den Hertong apud Debiasi (2001) ao afirmar que a interação e a troca de conhecimento entre as empresas, instituto de pesquisa, universidade e outras instituições, são o coração da análise dos processos de inovação. $\mathrm{O}$ mesmo ocorre com os cursos do SENAI -CETECEP que, mesmo sendo de nível técnico, está mais centrado para a realidade de manutenção e reparos de máquinas e equipamentos do que propriamente para questões de inovação tecnológica. Tal quadro evidencia, de forma geral, a despreocupação dos empresários em buscar soluções e aperfeiçoamento em produtos, processos, estrutura de ensino e pesquisa de nível técnico e superior, com o desenvolvimento de novas habilidades e competências necessárias ao processo de inovação.

Face aos aspectos apresentados, infere-se que o aglomerado produtivo de Telêmaco Borba apresenta-se como uma concentração de empresas preocupadas com os requerimentos do processo produtivo, podendo assim ser considerado como um aglomerado produtivo em potencial. Embora exista uma concentração de empresas com atividades produtivas e presença de algumas 
características em comum em seu sistema produtivo e organizacional (por exemplo, a maioria são pequenas e médias empresas localizadas no mesmo município), há muitas dificuldades a serem superadas como: infra-estrutura, desenvolvimento tecnológico, formação de mão-de-obra especializada, busca de políticas que possam reajustar ao setor e viabilizar o seu crescimento, bem como à conscientização por parte dos empresários de que se faz necessário à integração entre as empresas na busca de ações coletivas, exigindo por sua vez transformações culturais significativas em direção à cooperação.

\begin{abstract}
This work has as its objective to identify the forms of inter-enterprise relations, as well as verifying the factors that limit companies of a Cluster to adhere to more solid relationships of interaction that are capable to develop innovation. The field research contemplated a universe of 36 micro and small companies who act in the lumber sector. A questionnaire with structuralized and written questions was used sequentially. It consists in a quantitative and qualitative research, of interpretative nature, using a survey. One of the main results, evidenced that although the advantages cited in literature, the Productive Cluster in study does not show itself as a facilitator mechanism of the joint process and interactive learning, taking advantage in the internal environment of the companies in mechanisms of learning by doing method, gotten by the accumulated experiences and acquired local abilities, making possible technological definition and adaptations and improvements. Although the study verifies that one significant parcel of the companies are worried about product, process or equipment innovation, a complete absence of activities of R\&D technology is observed integrated next to technological centers of research and university of the type learning by interacting.
\end{abstract}

Key-words: productive agglomerations; interactive learning; innovation; clusters.

\title{
Referências
}

AMATO NETO, J. Redes de cooperação produtiva e clusters regionais: Oportunidades para as pequenas e médias empresas. São Paulo: Atlas, 2000.

BARQUERO, A.V. Desenvolvimento endógeno em tempos de globalização. Porto Alegre: Fundação de Economia e Estatística - Universidade Federal do Rio Grande do Sul, 2002.

BRITO, J. Características estruturais dos clusters industriais na economia brasileira. Rio de Janeiro: UFRJ/IE, 2000. (Nota técnica, 29/00). Disponível em: http://www.ie.ufrj.br/redesist/P2/textos/NT29.PDF. Acesso em: 08 fev.2005.

CAMPOS, R.R.; CÁRIO, S.F.; NICOLAU, J.A.; VARGAS, G. (2002). Aprendizagem por interação: Pequenas empresas em sistemas produtivos e inovativos locais. In: LASTRES, H. M. M; CASSIOLATO, J. E.; SZAPIRO, M.; ALBAGLI, S.; LEGEY, L.R.; LEMOS, C.; MACIEL, M.L. Proposição de políticas para promoção de sistemas produtivos locais de micro, pequenas e médias empresas. Rio de Janeiro: UFRJ/IE, 2002.

CASSIOLATO, J.E.; SZAPIRO, M. Aglomerações e sistemas produtivos e inovativos: Em busca de uma caracterização voltada ao caso brasileiro. In: LASTRES, H. M. M; CASSSIOLATO, J. E.; SZAPIRO, M.; ALBAGLI, S.; LEGEY, L.R.; LEMOS, C.; MACIEL, M.L. Proposição de políticas para promoção de sistemas produtivos locais de micro, pequenas e médias empresas. Rio de Janeiro: UFRJ/IE, 2002.

CONCLA, Comissão Nacional de Classificação. Classificação Nacional de Atividades Econômicas - CNAE. Disponível em http://www.ibge.gov.br/concla/ Acesso em: 08 set.2006.

DEBIASI, F. Modelo de identificação e mapeamento de clusters para elaboração de propostas de desenvolvimento regional. Dissertação (Mestrado em Engenharia de Produção) - UFSC/Universidade Federal de Santa Catarina, Florianópolis, 2001.

GIANESI, I.G, CORRÊA, H.L. Administração estratégica de serviços: Operações para a satisfação dos clientes. São Paulo: Atlas, 1996.

GIL, A. C. Métodos e técnicas de pesquisa social. São Paulo: Atlas, 1999. 
HADDAD, P.R. Cluster e Desenvolvimento Regional no Brasil. Revista Brasileira de Competitividade. Belo horizonte: Instituto Metas, ano 1, n⿳2 2, Agost/Set.2001.

LEMOS. C.R. Micro, pequenas e médias empresas no Brasil: Novos requerimentos de políticas para a promoção de sistemas produtivos locais. Tese (Doutorado em Engenharia de Produção) - UFRJ/Universidade Federal do Rio de Janeiro, Rio de Janeiro, 2003.

LUNDVALL, B.; JOHNSON, B. Promoting innovation systems as a response to the globalising learning economy. Rio de Janeiro: UFRJ/IE, 2000. (Nota técnica, 04/2000). Disponível em: http://redesist.ie.ufrj.br/nts/nt2/NT4.PDF. Acesso em: 02 nov. 2005.

PORTER, M.E. Competição: Estratégias competitivas essenciais. Rio de Janeiro: Campus, 1999.

SCHMITZ, H. e NADVI, K. Clustering and Industrialization: Introduction. World Development. UK, v. 27, n. 9, p.1503-1514, 1999.

SEPL, Secretaria do Estado do Planejamento e Coordenação Geral; IPARDES, Instituto Paranaense de Desenvolvimento Econômico e Social. Identificação, caracterização, construção de tipologia e apoio na formulação de políticas para os Arranjos Produtivos Locais (APLs) do Estado do Paraná: Etapa 3 - Caracterização estrutural preliminar dos APLs pré-selecionados e nota metodológica para os estudos de caso. Curitiba: IPARDES, 2005.

SUZIGAN, W. APLs geram desenvolvimento. Revista Tecnicouro. Rio Grande do Sul, n.9, v.25, p.64 - 72 , Nov./Dez.2004.

\section{Dados dos autores:}

Nome completo: Leozenir Mendes Betim

Filiação institucional: CESCAGE

Departamento: Administração

Função ou cargo ocupado: Professora

Endereço completo para correspondência (bairro, cidade, estado, país e CEP): Ernani Batista Rosas, 3131, Blc.24 - Apto 37- Jardim Carvalho- Ponta Grossa/PR- CEP: 84015-900

Telefones para contato: (42) 9928-73-87; (42) 3219-80-72

e-mail: leo@cescage.edu.br

\section{Nome completo: Luis Mauricio Martins de Resende}

Filiação institucional: Universidade Tecnológica Federal do Paraná

Departamento: Programa de Engenharia de produção

Função ou cargo ocupado: Professor

Endereço completo para correspondência (bairro, cidade, estado, país e CEP): Av Monteiro Lobato, s/n - Km 04 CEP 84016-210 - Ponta Grossa - PR - Brasil

Telefones para contato: (42) 3220-4879

e-mail: $\underline{\text { lmresende@utfpr.edu.br }}$

Recebido para publicação em: 20/08/2010

Aceito para publicação em: 08/10/2010 